\title{
DEVELOPMENT OF APPROACHES TO PERSONNEL MANAGEMENT BEFORE THE PHASE OF THE MERGING PROCESS OF ENTERPRISES
}

\author{
Alla Cherep', Valentina Helman², Andrii Lynenko³
}

\begin{abstract}
Purpose. Modern business is increasingly focusing on alternative options for integration among corporate growth stimulation measures, in particular, through the formation of new strategic alliances, collaboration with enterprises and start-ups, as well as through mergers or acquisitions. That is why the research is aimed at solving problems of effective management of personnel in the process of merger of enterprises, in particular, in the machine building industry by merging, takeover or otherwise integrating business, as well as at developing modern approaches to personnel management in business mergers. HR systems should be adapted to the specific conditions of the merger or takeover of business structures, taking into account the relevant phases of the process of enterprise integration. Methodology. The methodological basis of the study consist of general scientific methods of analysis and synthesis, comparative study of the economic processes in the management of personnel in the conditions of mergers and takeovers of business structures. The empirical method is used to describe the problem of taking into consideration the management of particular features of individual phases of the process of enterprise integration. This monographic study of a defined problem has given an opportunity to obtain results of practical significance and scientific value. Results. The necessity of taking into account the specifics of the individual phases of the merger of enterprises in the management of integrated business personnel is substantiated. It has been obtained the further development of HR-tools, HR-methods, and HR-practices, the use of which during the business mergers will help to address the shortage of key skills and improve the efficiency of the integrated business. Practical implications. Applied guidance on human resources management can be successfully implemented in the machine-building enterprises of Ukraine in the process of their merger with the aim of creating a more efficient integrated entity. The results of the study provide an opportunity to clearly outline the peculiarities of the phases of the process of business combining, which necessitate the use of appropriate HR-tools, HR-methods, and HR-practices for the integrated business. Originality. The novelty of the results is the conceptual scheme of the personnel decision-making in the conditions of organizational changes in the combination of machine-building enterprises taking into account the three-phase process of their integration. The article focuses on the crucial importance of using HR-practices in accordance with the phases of the merger process to ensure the success of mergers and takeovers, resulting in new business combinations. The article explores HR-practices in the field of mergers and takeovers, which create new business combinations. The expediency of using HR-tools and HR-methods is proved for domestic enterprises operating in the field of machine-building, which are interested parties of integration processes. The developed human resources recommendations make it possible to increase the organizational efficiency of functioning of newly formed and already existing associations of machine-building enterprises.
\end{abstract}

Key words: HR-tools, HR-methods, HR-practices, mergers and takeovers, business integration, personnel management, business combinations.

JEL Classification: G34, M12, M21

\footnotetext{
Corresponding author:

${ }^{1}$ Zaporizhzhia National University, Ukraine.

E-mail: cherep.av.znu@gmail.com

${ }^{2}$ Zaporizhzhia National University, Ukraine.

E-mail: smsvell@yandex.ua

${ }^{3}$ Zaporizhzhia National University, Ukraine.

E-mail: konf.econom.znu@gmail.com

ORCID: https://orcid.org/0000-0001-6473-6074
} 


\section{Introduction}

Today, the practice of concluding merger or takeover agreements has extended to Ukrainian business as well. The most widespread sense of mergers/takeovers is one of the additional ways of consolidating business, expanding enterprise activities and spheres of influence in a single market.

The negative aspects include the fact that the M\&T process is quite lengthy and may take years; besides, large companies are finding it more difficult to achieve a quick reaction to the variability of the environment. Taking into account "external variables" and "internal variables" is important in such processes and they determine the success of integration. Importance is given to the role of human resources in the processes of mergers and takeovers, an adaptation of personnel management systems to specific conditions of mergers or takeovers of business structures.

The main role of HRM in the process of merging companies is to mitigate the possible negative impact of processes of changing ownership or form of management on organizational effectiveness by creating a mechanism for reducing ambiguity that occurs in the process of organizational change. This provides a better understanding of the integration of enterprises by employees and their managerial staff and increases the motivation to the successful integration of enterprises through mergers or takeovers (Correia, Cunha, Scholten, 2013).

The studies of theoretical, methodological, and practical issues related to the role of HRM in M\&Ts, how HRM centrality affects the relation between ownership change and performance, are explored in the work of domestic and foreign scientists, including P. M. Bal, P. Christman, M. Cording, M. F. Correia, R. C. Cunha, L. Dorenbosch, S. Jackson, D. R. King, C. Lakshman, C. K. Love, M. Scholten, R. Schuler, O. V. Stalinska, M. L. Tsurkan, and others.

After analysing different approaches of scientists to determining the specifics of human resource management in the context of organizational change, one is clear that today there is a need for in-depth research and further development of the use of HRpractices, HR-tools, and HR-methods for enterprises operating in the field of machine-building and which are stakeholders of the integration processes.

\section{Causes of inadequate attention to personnel management in the process and after the merger of enterprises}

Mergers and takeovers of entrepreneurial structures are quite popular forms of organizational change in the business. However, such situations of mergers and takeovers are accompanied by radical changes, which provoke problems for the established work of enterprises that are united in the organizational sense, creating powerful internal turbulence (Cording, Christman, King, 2008; Lakshman, 2011).

Integration processes are widespread today in the business environment around the world, and the machine-building is no exception. However, in Ukraine, the tendency towards the merger of enterprises is not so tangible; however, it still has a significant impact on the development of the economy as a whole. Thus, according to the results of the annual survey of executives of the largest companies in the world conducted by $\mathrm{PwC}$ analysts in 2018, in Ukraine $30 \%$ of the polled CEO ( $49 \%$ in the world) chose the creation of the new strategic unions among the measures to stimulate corporate growth over the next 12 months, the collaboration with other enterprises and startups was chosen by $18 \%$ (in the world - 33\%), and mergers and takeovers were selected by $14 \%$ (in the world $42 \%)$. The analysed data are grouped in Table 1.

Table 1

The results of the survey of $\mathrm{CEO}$ in the world and Ukraine on measures to stimulate corporate growth through integration, percentage of respondents

\begin{tabular}{|l|c|c|}
\hline \multicolumn{1}{|c|}{ Measures to stimulate corporate growth } & World & Ukraine \\
\hline New strategic alliances & 49 & 30 \\
\hline Collaboration with businesses and startups & 33 & 18 \\
\hline Mergers and acquisitions & 42 & 14 \\
\hline
\end{tabular}

The more clearly indicated tendencies for the integration of enterprises are represented in Figure 1.

Consequently, a significant proportion of the surveyed CEO of large Ukrainian enterprises envisages participation in the integration processes during the next year, therefore, attention to the problems of effective management of personnel during organizational changes caused by mergers, takeovers or other associations of enterprises is justified by the objective need to ensure the successful integration of business.

Mergers and takeovers in business can be successful but they can also lead to major failures. Mergers and takeovers of enterprises that are conducted quickly without proper organizational support and appropriate training of staff are generally doomed to failure. Some problems in the merger of enterprises can be explained by financial and market factors, but a significant number of failures is due to ignoring questions related to human resources management in the process of integration and after the formation of a business association. Numerous studies confirm the need for systematic consideration of various problems and activities in the area of human resources associated with mergers and takeovers by participants in business associations. In fact, recently the research in sectors has shown that $50-70 \%$ of all mergers, takeovers, and other corporate transformations do not reach the desired level of success, primarily due to human resources problems of integrated business formations (Tsurkan, 2017). 


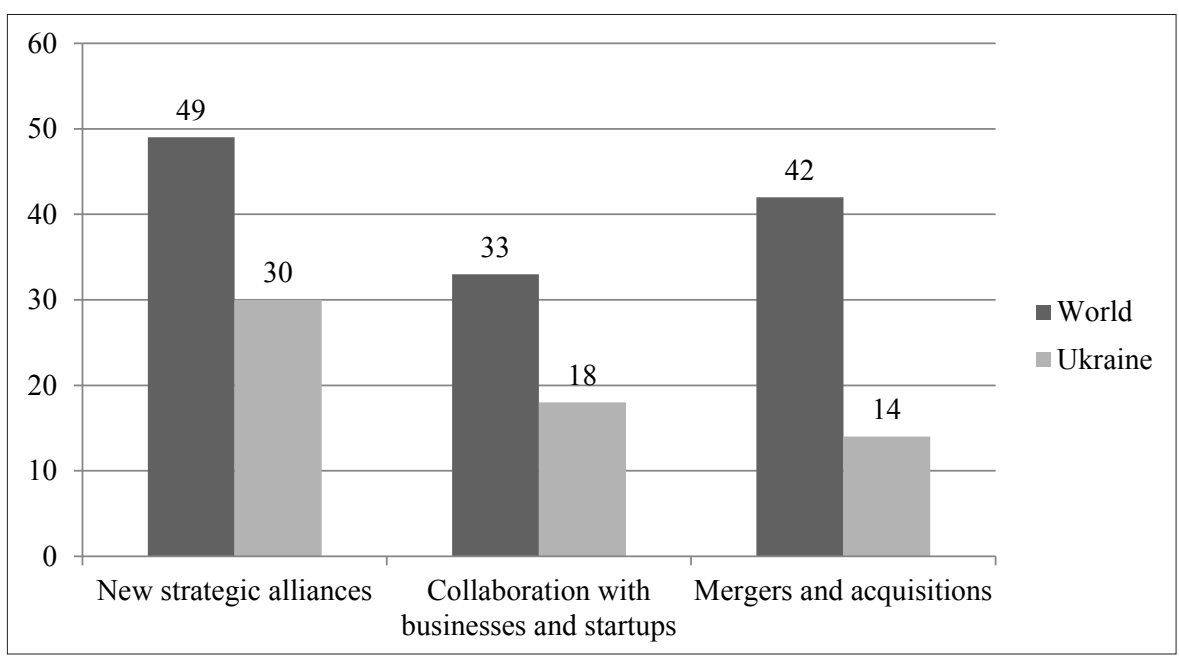

Figure 1. Trends in the business integration in the world and in Ukraine according to the survey results of the $\mathrm{CEO}$ of large enterprises, percentage of respondents

There are many reasons that cause some disregard for human resources management in the process of merging enterprises. The main reasons for this are:

- lack of awareness that human resources have a decisive influence on the success of the processes of merging enterprises, in particular, of the machine-building industry;

- lack of universal models or tools for managing human resources in mergers or takeovers;

- the emphasis in mergers and takeovers, as a rule, shifts to other problems, rather than human resources, their adaptation to change and motivation to work effectively under new conditions;

- insufficient study of the peculiarities of personnel management in the process and after the merger of enterprises, in particular in Ukraine.

Experts point out that in the merger or integration of enterprises in any other way, human resources professionals must participate before, during, and after the merger of enterprises into a new integrated business structure. HR-systems should be adapted to the specific conditions of the merger or takeover of business structures. Research shows that a merger of enterprises, whose HR-practices are fully integrated, goes more smoothly and employees remain content and motivated at any transition (Schuler, Jackson, 2001).

\section{The need to take into account the three phases of mergers or takeovers in personnel management}

To improve the efficiency of M\&T processes, the top management of enterprises should use personnel methods that develop integration opportunities, in particular, after the merger of machine-building enterprises.

Taking into account the experience of enterprises that take part in mergers and takeovers, a three-phase model of enterprise merger can be distinguished, which includes the following phases: the first before the merger; the second - the merger that is the integration of partners; the third phase - after the merger, which involves the development of a new organizational structure. Typically, these three phases cover a wider range of business functions, namely business strategy, finances, marketing, sales, IT and production, but according to the merger or takeover phase, there are some questions that reflect problems that are most closely related to human management resources in the integration process (Bal, Dorenbosch, 2015).

According to the information above, it is important to take into account the peculiarities of the phases of mergers or takeovers, as well as the specifics of the management of human resources in the process of making personnel decisions in the context of organizational changes. The conceptual scheme of personnel decisions in the conditions of organizational changes during the merger of machine-building enterprises is represented in Figure 2.

Thus, the first stage is a preliminary merger that involves the planning of a merger or takeover process. At the first stage, there are many problems with the staff, as well as other related issues. For example, one of the reasons for a merger is to try to get the key advantage of another company, which is often manifested in talented employees who will be very useful in the future for the newly established integrated business structure.

The problem with the personnel faced by enterprises involved in mergers and takeovers in the first phase of planning organizational changes can be as follows: - the formation of a team on personnel or the definition of a leader in the process of merger or takeover; - planning and coordination of the process of merger or takeover of enterprises in the field of machine-building; 


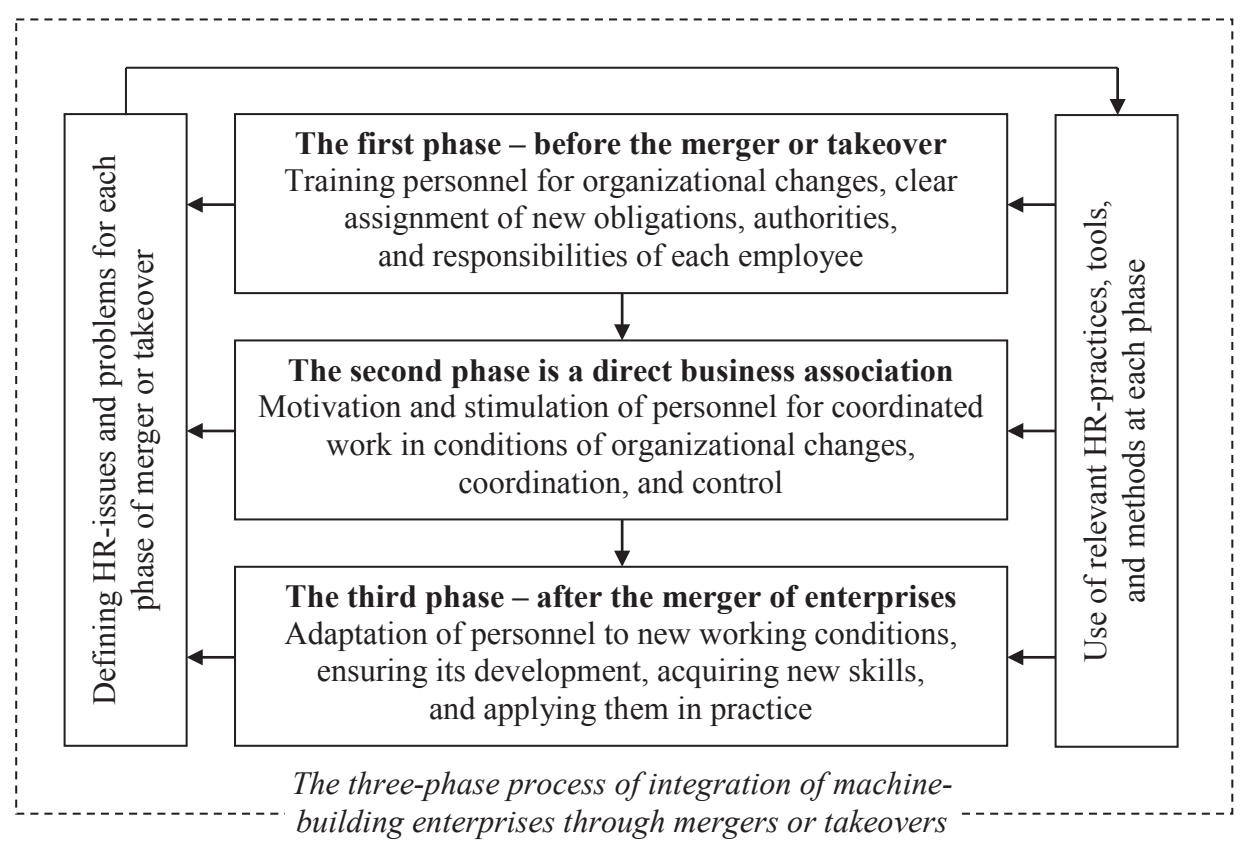

Figure 2. Conceptual scheme of personnel decision-making in the conditions of organizational changes in the merger of machine-building enterprises

- the need for a comprehensive study of other processes for the integration of business.

Integration of the business partners is the second and probably the most important phase, which includes various activities of participating companies. In general, integration is a process, due to which two companies combine after the announcement of mergers or takeovers. It is desirable at this stage to choose an integration manager, which should focus only on a specific process of merger and takeover. The following problems with personnel issues that emerge at the enterprises at the integration phase of the partners are: - problems of designing effective teams;

- creation of a new organizational structure for the management of integrated business formation;

- problems with retaining the key employees of the merged enterprises;

- the motivation of workers in the new conditions of their work;

- effective management of change processes;

- the need for well-considered personnel policy.

One of the most important tasks for the personnel department or personnel manager is to solve who will stay and who will go. The important targets of the personnel service include: a selection of candidates, the creation of new teams, emphasis on communication, the creation of a new corporate culture and organizational management structure.

The last stage - the third one is characterized by the creation of a new integrated business entity. In the process of creating new combinations, there are problems of adjustment, working out all functions and "fine" settings. The following points can be attributed to staff problems that arise at the last phase of mergers or takeovers:

- strengthening the leadership and staffing of the merged enterprise;

- assessment of the new corporate culture;

- an analysis of new development strategies and security structures etc. (Bal, Dorenbosch, 2015).

Among the important tasks faced by the personnel service at this phase of the association of machinebuilding enterprises, there are as follows: designing and creating a new structure; reconciliation of two new cultures with each other; mandatory consideration of the interests of key stakeholders in business integration.

\section{Possibilities of solving problems of personnel management in the merger of enterprises}

Analysing the potential threats to the growth prospects of enterprises, according to a survey of their CEO, conducted by researchers at PwC (2018), one can be stated that the problem of the shortage of key skills specialists in Ukraine ranked second place by its importance after social instability. Problems with the lack of qualified specialists, their attraction, keeping in the company, and effective management of personnel, in particular, in the process of merger or takeover, are also very topical for top management of enterprises in Central and Eastern Europe (Figure 3).

Problems of providing integrated business with qualified specialists with key skills can be successfully solved if machine-building enterprises - members of the association will implement modern HR-tools and 


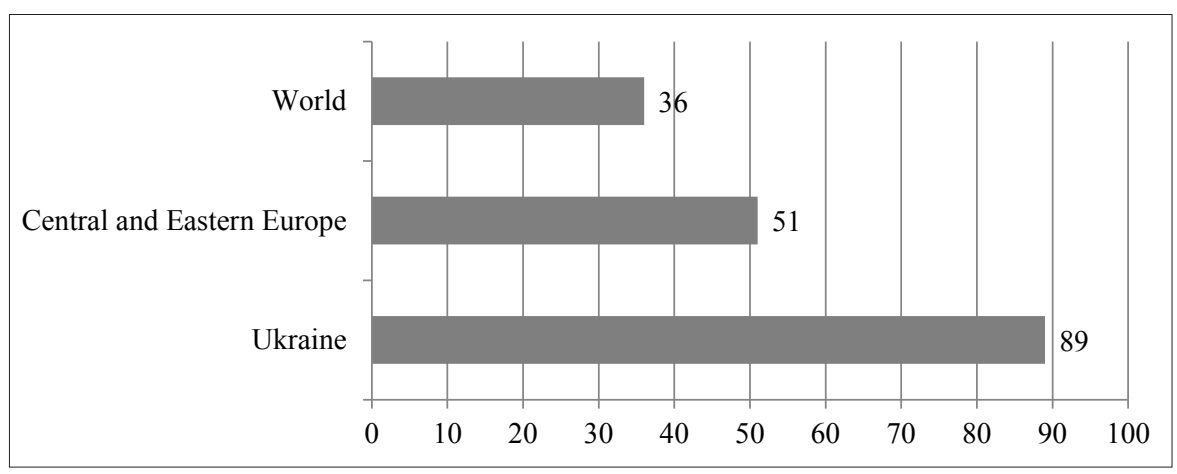

Figure 3. Percentage of CEO interviewed in 2018 who consider the lack of key skills to threaten the prospects for their business growth

methods of personnel management, with consideration of the three phases of mergers or takeovers that have already been characterized.

In addition, if the association of machine-building enterprises takes place at the level of international cooperation, the following features of the human resources management of a transnational corporation (Stalinska, 2018) should be taken into account:

- the cosmopolitan nature of employees, the existence of workers, who are mostly members of a high-level elite who are constantly moving from one country to another; - the existence of significant differences in the cultural background of workers;

- the existence of a difference in remuneration and other privileges between foreign and local staff;

- widespread use of IT-technologies for maintaining communication with the personnel of the integrated business-structure of the international level;

- the need for an effective strategy of convergence and harmonized management of the various functions of staff across borders.

Analysis of the best HR-practices in companies proves the effectiveness of informing employees ahead of time about planned future changes. The top management should have an initial plan, which specifies the timing for employees to be informed about organizational changes. Such measures make it possible to minimize worries and circulation of rumours by workers, as well as ensure that staff is focused on their job functions (Love, 2000).

Particular attention should be paid to retaining the best employees at work. Talented employees play a key role in successful restructuring but they are often one of the first freed because of the inexplicability of future prospects in the enterprise. At the same time, in order to maintain the moral standing of employees, decision-making by management should be impartial and consistent for all employees, excluding particular attitudes towards some of them. Creating the conditions of justice is to distribute rewards and punish those who deserve them. Even in times of change, it's important to mintain an appropriate level of corporate culture.

\section{Conclusions}

Personnel aspects of mergers and takeovers may be offset by legal and financial implications but the success of such a process, as a rule, depends on staff, sustained support for business expansion, in particular, HRmanagement. Employees should be seen as a source of growth, sustainability or success.

The novelty of the results of the conducted research is the conceptual scheme of the personnel decisionmaking in the conditions of organizational changes in the combination of machine-building enterprises taking into account the three-phase process of their integration, in particular, each phase such as "before merger or takeover," directly "during the business combination" and "after the merger of enterprises" has features of management of human resources. The first phase involves training personnel for organizational changes, a clear division of new authorities, powers, and responsibilities of each employee. The second phase focuses on motivating and stimulating staff to work together in conditions of organizational change, coordination, and control. The third phase should adapt the staff to the new conditions of work, to ensure its development, acquisition of new skills, and their application in practice.

Besides the application of HR-practices (e.g. a plan for informing employees about the key moments and timing of organizational changes, keeping the best employees), HR-tools (such as benchmarking, planning, a balanced HR-system), and HR-management techniques in the process of consolidation of machine-building companies can increase the success of the integration of participating companies, as well as improve the indicators of organizational efficiency of the newly created business structure accordingly.

Effective governance is key to merge or takeover and identify a new culture. Success in any association is defined by financial, technological, and personnel aspects. Today HR-function becomes a strategic player in the business. 
Further research will focus on identifying the characteristics of personnel management depending on the forms of enterprise mergers, for example, the creation of a cluster or strategic alliance of enterprises, or the formation of a consortium on a temporary basis, as well as the development of methodological approaches to calculating the cost-effectiveness of the application of modern methods and techniques of personnel management in integrated business structures.

\section{References:}

Bal, P. M., Dorenbosch, L. (2015). Age-related differences in the relations between individualised HRM and organisational performance: a large-scale employer survey. Human Resource Management Journal, 25(1), 41-61.

Cording, M., Christman, P., King, D. R. (2008). Reducing Causal Ambiguity in Acquisition Integration: Intermediate Goals as Mediators of Integration Decisions and Acquisition Performance. Academy of Management Journal, 51(4), 744-797.

Correia, M. F., Cunha, R. C., \& Scholten, M. (2013). Impact of M\&As on organizational performance: The moderating role of HRM centrality. European Management Journal, 31, 323-332.

Lakshman, C. (2011). Postacquisition cultural integration in mergers \& acquisitions: A knowledge-based approach. Human Resource Management, 50(5), 605-623.

Love, C. K. (2000). Mergers and Acquisitions: the Role of HRM in Success. Ontario: IRC Press.

Schuler, R., \& Jackson, S. (2001). HR Issues and Activities in Mergers and Acquisitions. European Management Journal, 19(3), 239-253.

Stalinska, O. V. (2018). Osoblyvosti upravlinnia personalom na bahatonatsionalnomu pidpryiemstvi [Particularities of personnel management at a multinational enterprise]. Economy and Society, 14, 735-739.

The Anxious Optimist in the Corner Office. What's on the mind of 1,293 CEOs around the world? PwC's 21 st CEO Survey. (2018). Kyiv: PwC Ukraine. Retrieved from https://www.pwc.com/gx/en/ceo-agenda/ceosurvey/2018/ua Tsurkan, M. L. (2017). Innovacijni mekhanizmy upravlinnja rozvytkom personalu korporatyvnykh pidpryjemstv intehrovanykh kholdynhiv [Innovative management mechanisms for the personnel development of corporate enterprises by integrated holdings]. Thesis for a degree of candidate of economic science. Pryazovskyi State Technical University, Mariupol. 